\title{
PENERAPAN MODEL WATERFALL PADA APLIKASI BANK SAMPAH
}

\author{
Nur Rofiq ${ }^{1}$, Agung Perdananto ${ }^{2}$, Nurjaya ${ }^{3}$ \\ 1,2,3 Teknik Informatika \\ ${ }^{1,2,3}$ Universitas Pamulang, Tangerang Selatan, Indonesia \\ Correspondence email: dosen00376@ unpam.ac.id
}

Article history: $\quad$ Submission date: Juni 13,2021 Revised date: Juni 28, $2021 \quad$ Accepted date: Juni 30, 2021

\begin{abstract}
The Waterfall Model is also very widely used by organizations and is developed with certain software whose results can overcome changes and weaknesses. This research is designed to manage the data of 'Jawara' customers because currently, they are still using a semi-computerized method that only writes them down in a book list. This study uses a qualitative approach with descriptive analysis with stages, namely system engineering, analysis, design, code generation, and the Waste Bank application testing. The application of the waterfall model in the Waste Bank information system application is a solution in the use of previously still recording customer waste deposits in Excel files, making quick and detailed waste price list reports, simplifying customer data processing, accelerating the search for required information and making it easier for customers to view a history of withdrawal and deposit transactions that previously still used semi-computerized methods. The result of this research is an application that has been made into a solution in making quick and detailed waste price list reports, simplifying customer data processing and speeding up information search, viewing withdrawal and deposit transaction history.
\end{abstract}

Keywords: Waterfall Model, Garbage Bank Application

\begin{abstract}
ABSTRAK
Model Waterfall juga sangat banyak digunakan oleh organisasi dan dikembangkan dengan software tertentu yang hasilnya dapat mengatasi perubahan dan kelemahan. Penelitian ini dirancang untuk mengelola data pelanggan 'Jawara' karena saat ini mereka masih menggunakan metode semi komputerisasi yang hanya menuliskannya dalam daftar buku.Penelitian ini menggunakan pendekatan kualitatif dengan analisis deskriptif dengan tahapan yaitu rekayasa sistem, analisis, perancangan, pembuatan kode, dan pengujian aplikasi Bank Sampah. Penerapan model waterfall pada aplikasi sistem informasi Bank Sampah merupakan solusi dalam penggunaan yang sebelumnya masih mencatat simpanan sampah nasabah dalam file Excel, membuat laporan daftar harga sampah yang cepat dan detail, mempermudah pengolahan data nasabah, mempercepat pencarian informasi yang dibutuhkan dan memudahkan nasabah untuk melihat riwayat transaksi penarikan dan penyetoran yang sebelumnya masih menggunakan metode semi komputerisasi. Hasil dari penelitian ini adalah aplikasi yang telah dibikin menjadi solusi dalam pembuatan laporan daftar harga sampah yang cepat dan rinci,mempermudah proses data nasabah serta mempercepat pencarian informasi,melihat histori transaksi withdraw dan penyetoran.
\end{abstract}

Kata Kunci: Waterfall Model, Aplikasi Bank Sampah

\section{PENDAHULUAN}

Classic life cycle atau siklus hidup tradisional yang dituangkan menjadi model waterfall adalah pengembangan atas perangkat lunak yang menitikberatkan melalui tahap-tahap yang sistematis dan secara berurutan. Analisis ini diawali dari proses pengumpulan kebutuhan, translasi kebutuhan perangkat lunak dalam tahap rancangan, pengkodean ke dalam tahap program serta logic dan fungsional pada tahap pengujian yang melalui serangkaian untuk mengidenfikasi kebutuhan pengguna atau konsumen tersebut pada tahap awal (Bassil, 2012; Husain, 2017). Model waterfall juga sangat banyak digunakan oleh organisasi dan dikembangkan dengan perangkat lunak tertentu yang hasilnya dapat mengatasi perubahan dan kelemahan-kelemahan pada perangkat lunak sebelumnya pada pengalaman atas penggunaan tidak hanya sekedar dari penelitian empiris atas pengolahan data (Petersen, Wohlin, \& Baca, 2009). Sistem 
pengolahan umumnya melakukan proses pengolahan data yang terdiri dari serangkaian kegiatan. Setiap aktivitas memiliki implementasi dalam bentuk kode lokal, layanan seperti web service atau proses lain yang berdiri sendiri, atau disebut sebagai bagian dari proses (United States Paten No. US20080270212A1, 2008). Oleh karenanya diperlukan penerapan model ini pada aplikasi tertentu untuk menjawab kebutuhan atau permasalahan yang timbul pada sistem yang sedang berjalan dan pemrosesan data yang hasilnya berupa informasi yang diharapkan dapat bermanfaat pengguna.

Pengguna yang selalu menjadi konsumen pada masyarakat dalam konteks luas tentunya sangat membutuhkan penerapan atau pengembangan sistem informasi yang dituangkan dalam model aplikasi untuk memproses dan menghasilkan informasi yang cepat, tepat, akurat dan informatif, khususnya dalam kebutuhan-kebutuhan primer. Sebagai contoh, penerapan aplikasi berbasis web dengan metode waterfall untuk sistem informasi inventori produk pangan (Tabrani, 2017). Perancangan e-Human Resource Management berbasis web untuk aktivitas pengelolaan karyawan yang meliputi perekrutan, cuti, lembur, mutasi hingga pemutusan hubungan kerja (Budiyantara \& Suhartono, 2017). Penerapan atas rekomendasi perumahan terbaik dalam sistem informasi untuk pengambilan keputusan pemilihan tempat tinggal (Wiguna \& Harianto, 2018). Penerapan aplikasi berbasis desktop dengan metode waterfall untuk sistem pelayanan medis (Darono, 2019). Penerapan aplikasi text editor JAVA 8.0.2 dengan metode waterfall untuk sistem pengelolaan klinik (Samsoni \& Budiawan, 2019). Implementasi sistem penjemuran otomatis dengan metode Naive Bayes untuk menjemur pakaian berbasis Arduino Uno (Jaiman, Syaminan, \& Wiguna, 2019). Pengembangan aplikasi berbasis web atas pembayaran tagihan listrik menggunakan metode waterfall (Fathony, Brata, \& Jonemaro, 2020). Beberapa contoh penerapan atau implementasi di atas, metode waterfall berdasarkan hasil penelitian dapat menghasilkan eksperimen yang dapat digunakan dalam kehidupan sehari-hari individu maupun organisasi dalam mengatasi permasalahan atau kebutuhankebutuhan pengguna.

Masalah-masalah yang kian kompleks dan dihadapi oleh masyarakat atau konsumen pada level paling bawah atau lingkup RT/RW masih sebagian besar belum dikelola dengan baik khususnya pengelolaan data warga (Sarmidi, Sri Mulyani, Wiyono, \& Gunawan, 2019), salah satunya adalah sistem informasi pada bank sampah. Sampah merupakan suatu bahan yang terbuang atau dibuang dari sumber hasil aktivitas manusia maupun proses alam yang belum memiliki nilai ekonomi (Kahfi, 2017). Masalah sampah timbul dengan adanya peningkatan timbunan sampah per hari, namun tak diimbangi dengan dukungan sarana dan prasarana penunjang yang memenuhi persyaratan teknis seperti halnya cakupan luas TPS, pengkategorian sampah, jenis penampungan sisa pengolahan, kapasitas, dan ketentuan teknis lainnya (SIPPa, 2017). Sampah yang tidak ditangani dengan maksimal akan berdampak pada masalah lingkungan. Masalah lingkungan sekarang ini bukan hanya tanggungjawab sekelompok orang, tetapi sudah menjadi tugas dan kewajiban semua masyarakat untuk tetap menjaga dan memeliharanya agar tetap asri.

Bank Sampah Jalan Cendrawasih Raya (JAWARA) yang terletak di Sawah Baru, Ciputat Tangerang Selatan.Masyarakat sekitar masih ditemukan membuang sampah bukan pada tempatnya di sungai atau saluran yang menyebabkan lingkungan menjadi kotor, timbulnya berbagai macam penyakit, pencemaran lingkungan dan rusaknya ekosistem. Bank Sampah ini mengelola sampah yang berjenis (nonorganik) seperti plastik, kertas, botol, dan sebagainya.Sebelum sampah yang disetor warga, warga diberikan rincian daftar harga sampah per barang.Sampah lalu dikumpulkan digudang penyimpanan dan ditabung sehingga dapat menghasilkan nilai ekonomis untuk nasabah. Untuk mendaftar menjadi nasabah, masyarakat hanya perlu KTP dan Nomor Telepon yang dapat dihubungi, Penabung pun disebut dengan nasabah mereka memiliki buku tabungan yang nantinya dapat diambil. Dari segi keseimbangan lingkungan, kesehatan dan kebersihan apabila sampah tidak dikelola dengan baik dapat menimbulkan pencemaran udara, pencemaran air dan pencemaran tanah. Berdirinya bank sampah karena adanya permasalahan lingkungan.Bank Sampah tersebut mengumpulkan sampah dari masyarakat (nasabah) maupun warga luar yang ingin menabung sampah nya di bank sampah yang nantinya akan ditimbang tempat gudang.

Beberapa penelitian tentang perancangan, pengembangan atas sistem informasi bank sampah telah dilakukan dengan model waterfall dan metode lainnya, seperti pembangunan Bank Sampah Ceria di Purwokerto, dimana hanya admin yang melakukan pengolahan data bank sampah. Sistem informasi bank sampah Bangkit yang berbasis web melibatkan 2 (dua) pengguna yaitu admin dan nasabah (Riyanto \& Kusumastuti, 2015). Penerapan model waterfall berbasis web pada untuk pengolahan sampah di salah satu wilayah DKI Jakarta. Sistem informasi bank sampah diterapkan berbasis web ini agar data bank sampah dapat diakses tanpa ada batasan waktu dan secara langsung (Samudi, Brawijaya, \& Widodo, 2018). Implementasi metode waterfall pada Dinas Lingkungan Hidup Kabupaten Asahan.Sistem e-Recycle Bank dapat mengelola data tabungan sampah jenis organik dan 
non-organik yang juga melibatkan 2 (dua) pengguna yaitu admin dan nasabah (Ramdhan, Yusda, Syafwan, \& Pratiwi, 2019). Pengelolaan bank sampah dengan metode waterfall berbasis framework 'Laravel'. Sistem informasi bank sampah melibatkan 2 (dua) pengguna yaitu teller dan nasabah (Putra \& Suardika, 2020).

Pentingnya penerapan metode waterfall dalam sistem informasi ini didesain untuk mengelola data nasabah 'Jawara', karena saat ini masih menggunakan cara manual yang hanya menuliskannya dalam daftar buku. Dengan diterapkannya sistem informasi pengolahan data nasabah ini diharapkan mampu mempermudah dalam pencarian data tetap serta mempercepat dalam menyediakan laporan data tetap setiap dibutuhkan.

\section{METODE PENELITIAN}

Jenis penelitian ini bersifat deskriptif yaitu pemaparan karakteristik tertentu atas fenomena yang memiliki tujuan tertentu, dan juga melakukan analisis, mengapa atau bagaimana hal itu terjadi (Ali \& Limakrisna, 2013). Pendekatan penelitian ini menggunakan basis kualitatif, dimana pengumpulan data dengan pengujian penelitian untuk dasar dalam pengambilan keputusan terhadap ekperimen seperti pengembangan sistem yang akan dibuat (Loeb, et al., 2017). Adapun tahapan-tahapan penelitian menggunakan model Waterfall yaitu:

1. Rekayasa Sistem Dan Analisis (system engineering), karena perangkat lunak adalah bagian dari sistem yang lebih besar, pekerjaan dimulai dari pembentukan kebutuhan-kebutuhan untuk seluruh element sistem dan memilah mana yang kemudian tepat untuk pengembangan sistem. Hal ini penting ketika perangkat lunak harus berkomunikasi dengan hardware, pengguna (user) dan basis data.

2. Analisis Kebutuhan Perangkat Lunak (analysis), pengumpulan kebutuhan dengan fokus pada perangkat lunak, yang meliputi domain informasi, fungsi yang dibutuhkan, unjuk kerja performasi dan antarmuka. Hasilnya harus didokumentasikan dan di revieu ke lapangan.

3. Perancangan (design), meliputi 4 (empat) atribut pada program yaitu struktur data, arsitektur perangkat lunak, prosedur detail dan karakteristik antarmuka. Proses design mengubah kebutuhankebutuhan menjadi bentuk karakteristik yang dimengerti perangkat lunak sebelum penulisan program.

4. Pembuatan Kode (coding), yaitu penerjemahan ke dalam bentuk yang dapat dimengerti oleh mesin, dengan menggunakan bahasa pemrograman yang pada penelitian ini menggunakan bahasa pemrograman PHP.

5. Pengujian (Testing), yaitu dilakukan setelah kode program selesai testing dapat dilakukan testing sendiri memfokuskan pada logika internal dari perangkat lunak, fungsi eksternal dan mencari segala kemungkinan kesalahan dan pemeriksaan agar sesuai dengan hasil yang diharapkan, dalam hal ini penulis menggunakan metode pengujian blackbox sebagai acuan apakah aplikasi yang dibuat sudah sesuai dan bebas dari error (Rosa \& Shalahuddin, 2014).

\section{HASIL DAN PEMBAHASAN}

Use case diagramadalah diagram yang mendeskripsikan kebutuhan sistem dari cara piker user, dan menunjukan relasi-relasi yang terjadi antara actor dengan use case dalam sebuah model sistem. Model dibentuk dengan elemen berupa bentuk, struktur, isi dan pengukuran dan batasan tertentu (Husain, 2019). Konstruksi dalam activity diagram ini bertujuan agar memudahkan dalam memahami langkah aliran kerja modeldiagram use case pada Bank Sampah 'Jawara'.

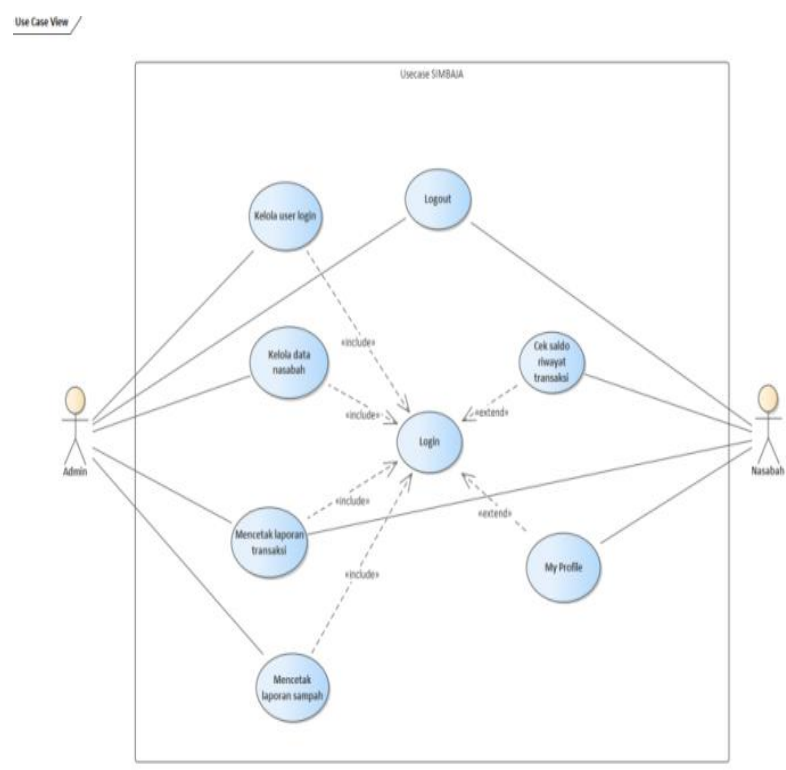

Sumber : (Nur Rofiq et al., 2021)

Gambar 1.Use Case Sistem Informasi Pengolahan Data Nasabah Bank Sampah 'JAWARA'

Class diagram adalah model statis yang menggambarkan struktur dan deskripsi class serta hubunganya antara class. Class diagram pada ERdiagram tidak terdapat operasi tapi hanya atribut. Class diagram ini memuat ketersediaan informasi pada rancangan aplikasi Bank Sampah 'Jawara'. 


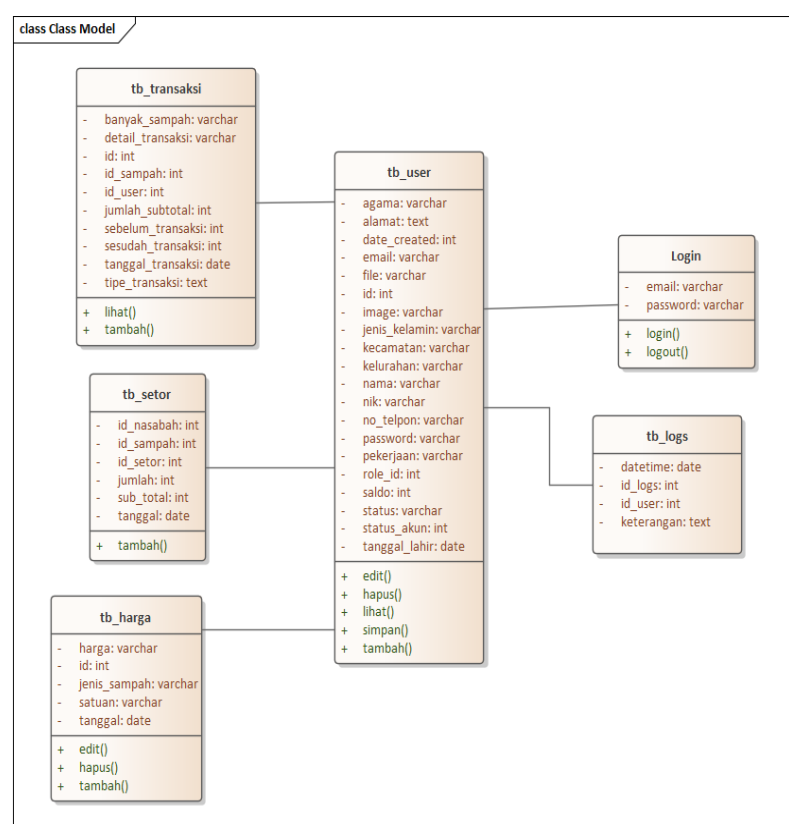

Sumber : (Nur Rofiq et al., 2021)

Gambar 2.Class Diagram

Perancangan basis data menggunakan entityrelationship diagram (ERD) yang menjelaskan model teknik pendekatan yang menyatakan hubungan suatu model yang menggambarkan objek dan relasi pada entity.

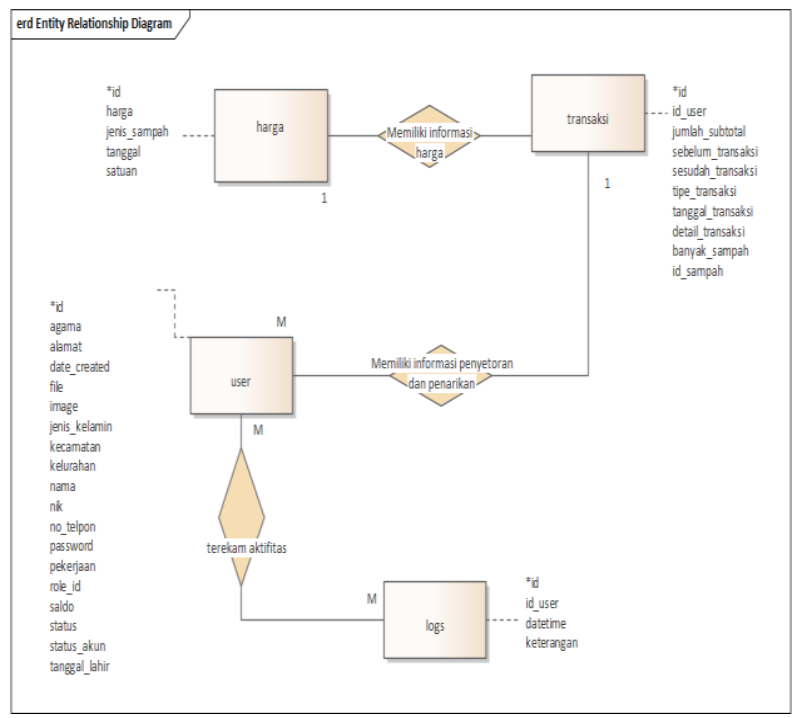

Sumber : (Nur Rofiq et al., 2021)

Gambar 3.ERD

Transformasi ERD ke logical record structure (LRS) pada Bank Sampah 'Jawara'.

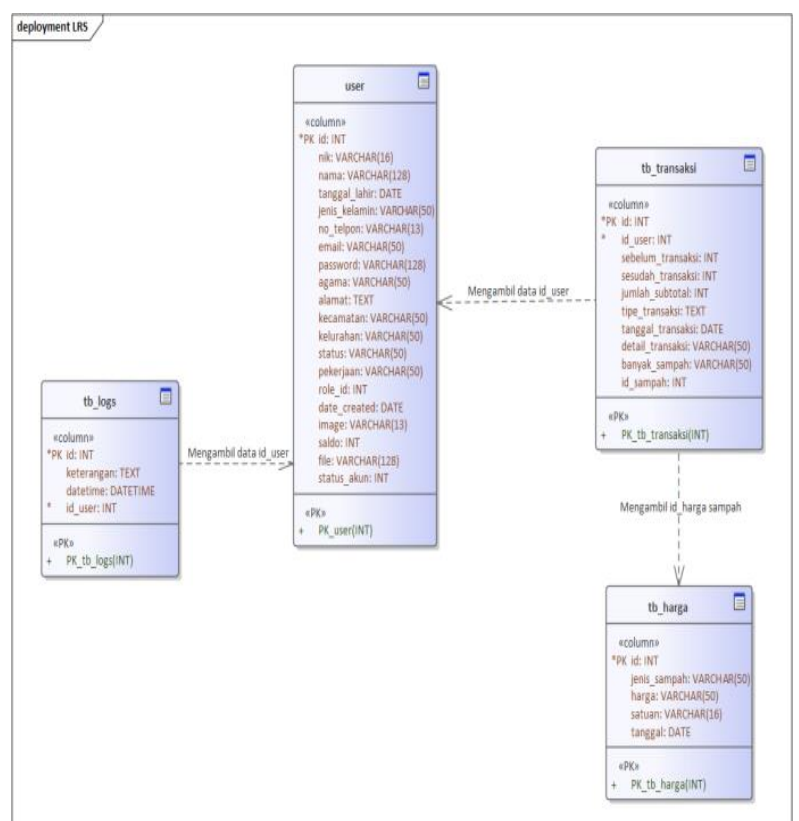

Sumber : (Nur Rofiq et al., 2021)

Gambar 4.Transformasi ERD menjadi Output LRS

Berikut ini hasil tampilan Halaman Utama pada aplikasi Bank Sampah 'Jawara' di Sawah Baru, Ciputat Tangerang Selatan:

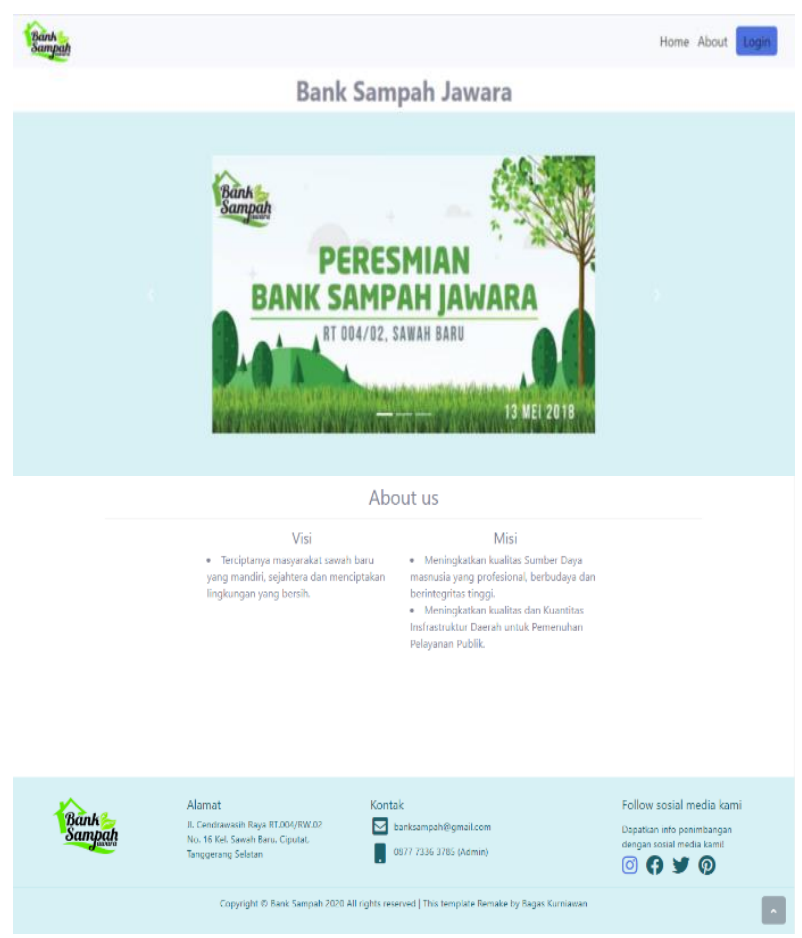

Sumber : (Nur Rofiq et al., 2021)

Gambar 5.Tampilan Halaman Utama 


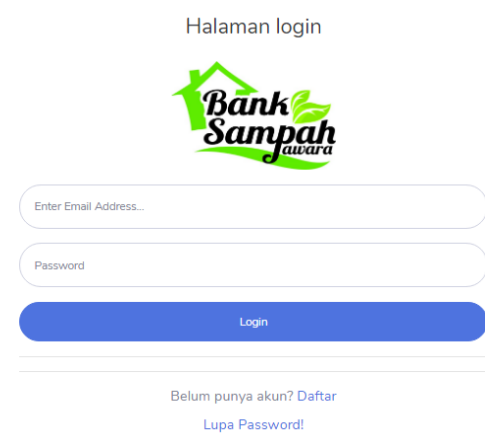

Sumber : (Nur Rofiq et al., 2021)

Gambar 6.Tampilan Halaman Login

Halaman login hanya dapat diakses oleh pengguna yang terdaftar. Cara login dibuat dengan sederhana untuk memudahkan user dalam mengaksesnya, yaitu dengan cara input email kemudian dengan mengisi password.

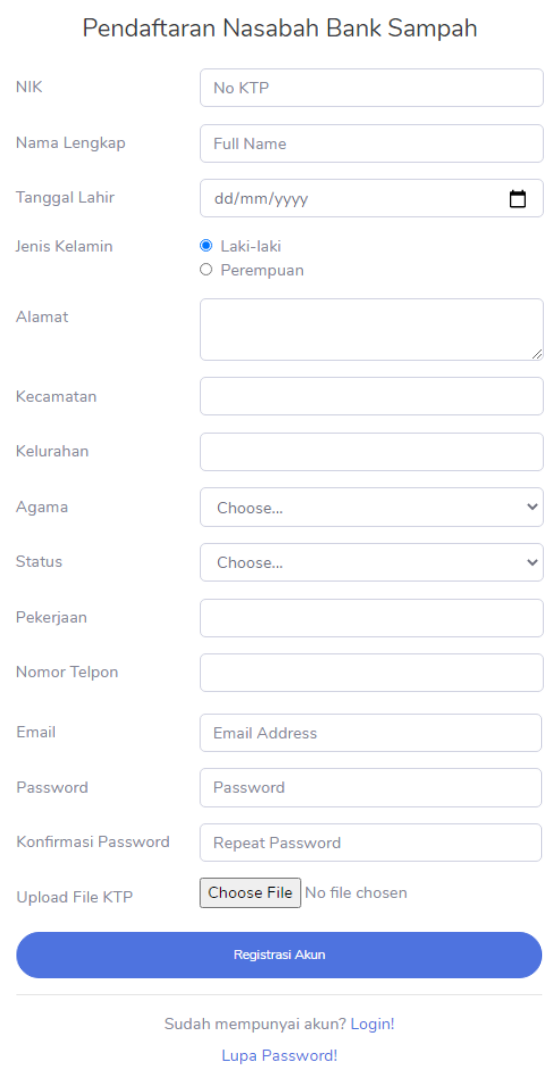

Sumber : (Nur Rofiq et al., 2021)

Gambar 7.Tampilan Halaman Form Registrasi

Halaman Registrasimenampilkan beberapa form yang harus dilengkapi oleh pengguna yang ingin melakukan registrasi menjadi nasabah bank sampah.

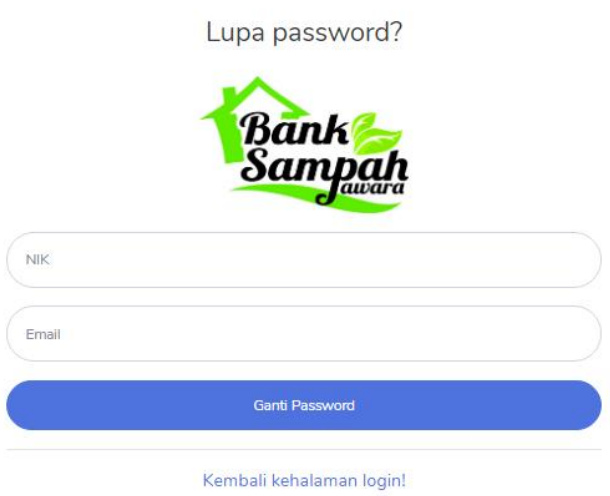

Sumber : (Nur Rofiq et al., 2021)

Gambar8.Tampilan Halaman Form Registrasi

Halaman Forgot Passwordmenampilkan hanya dapat diakses oleh pengguna yang terdaftar. Teknik ini dibuat dengan sederhana untuk memudahkan user dalam penggunaan, yaitu dengan cara input NIK kemudian Email.
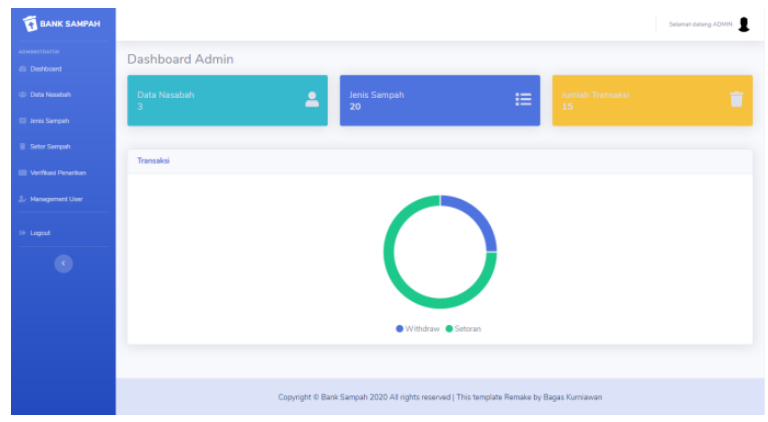

Sumber : (Nur Rofiq et al., 2021)

Gambar 9.Tampilan Halaman Dashboard Admin

Halaman Dashboard Admin menampilkan jumlah jenis sampah, data nasabah serta transaksi penyetoran sampah. Admin melakukan pendaftaran bagi setiap nasabah baru yang datang langsung ke tempat.

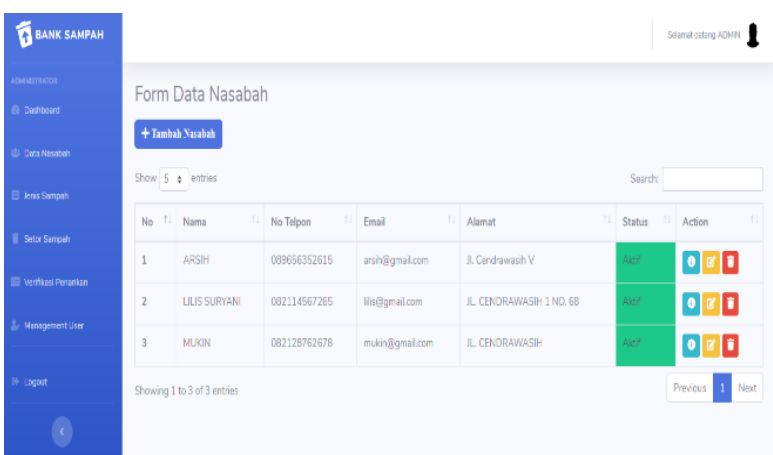

Sumber : (Nur Rofiq et al., 2021)

Gambar 10.Tampilan Halaman Data Nasabah 


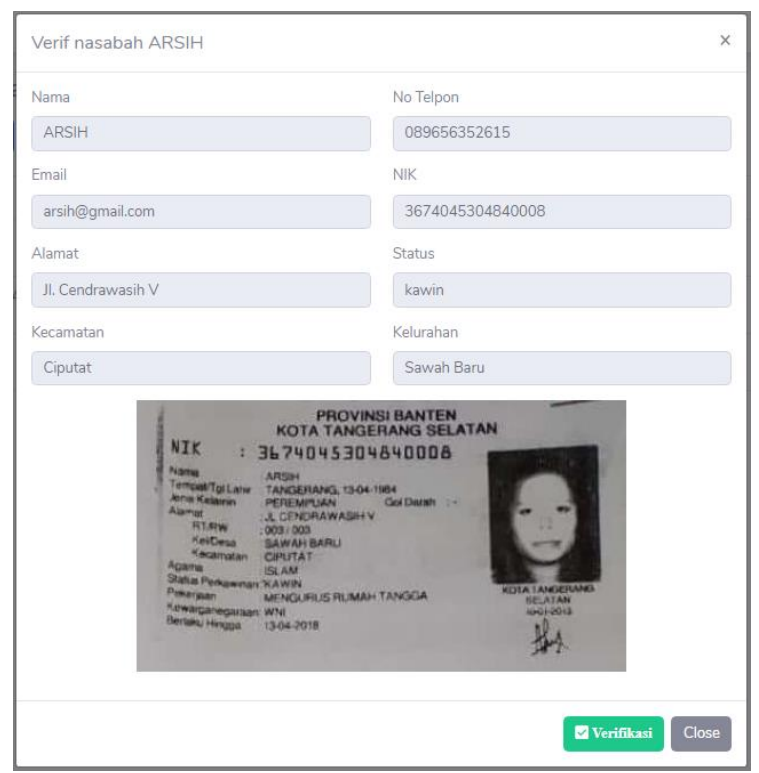

Sumber : (Nur Rofiq et al., 2021)

Gambar 11.Tampilan Halaman Verifikasi Nasabah

Halaman Verifikasi Nasabah ini berupa pop upuntuk menampilkan data informasi nasabah yang akan diverifikasi oleh admin.

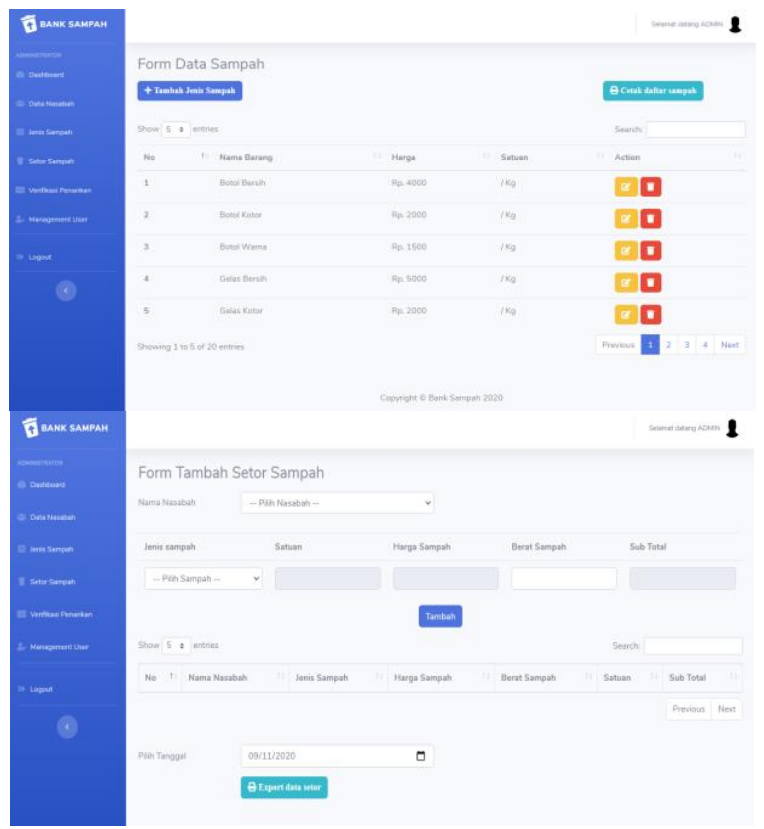

Sumber : (Nur Rofiq et al., 2021)

Gambar 12. Tampilan Halaman Form Data dan Penyetoran Sampah

Halaman form Data Sampah dan Penyetoran untuk menampilkan data sampah, dan dapat menambahkan, mengubah, menghapus data sampah serta cetak daftar harga sampah. Halaman ini juga untuk menambahkan data transaksi setor sampah nasabah yang datang ke penimbangan.

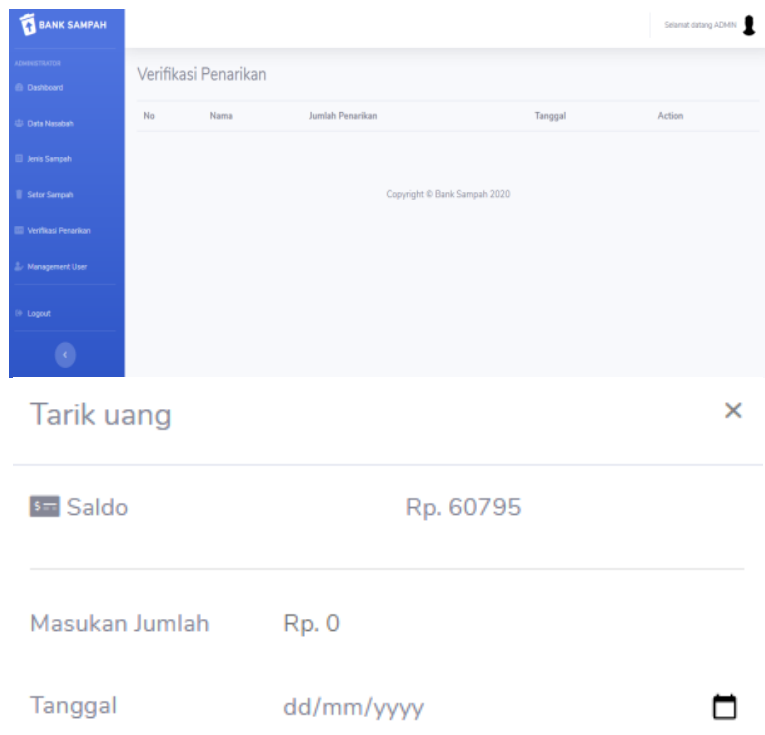

Sumber : (Nur Rofiq et al., 2021)

Gambar 13. Tampilan Halaman Verifikasi

Penarikandan Form Tarik Saldo

Halaman Verifikasi Penarikan untuk menampilkan data transaksi withdraw yang telah diajukan oleh nasabah.Halaman Tarik Saldoberupa pop upuntuk menampilkan jumlah saldo nasabah, dan dapat mengambil uang dengan mengisi jumlah dan menentukan jumlah uang yang ingin ditarik.

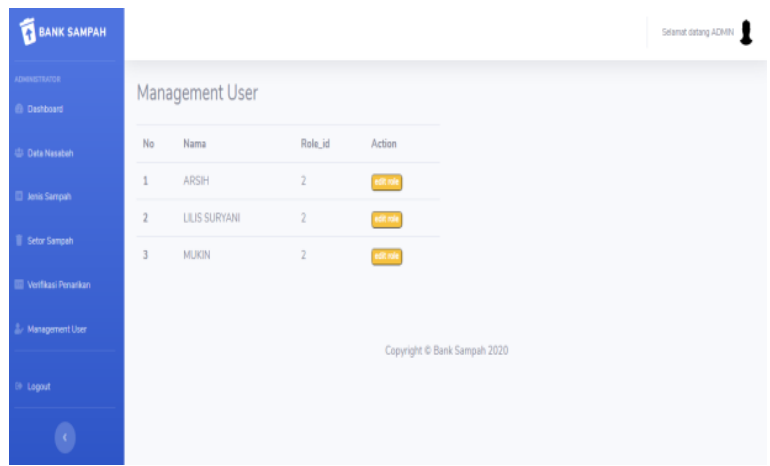

Sumber : (Nur Rofiq et al., 2021)

Gambar 14. Tampilan Halaman Management User

Halaman Management User untuk menampilkan data nasabah yang sudah terdaftar, admin dapat mengubah level akses nasabah menjadi admin. 

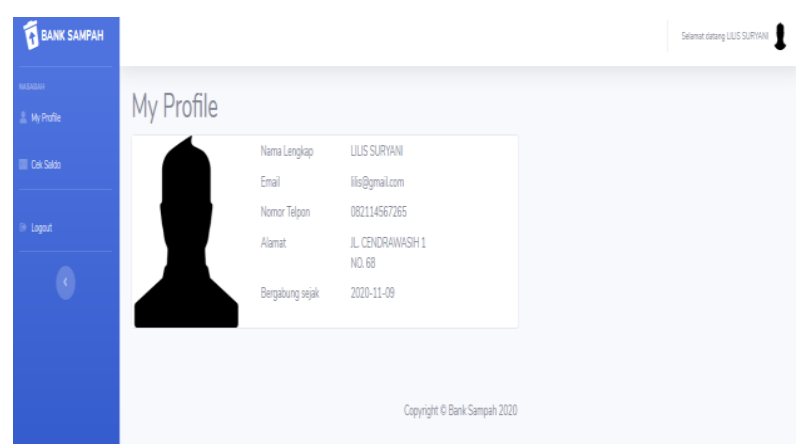

Sumber : (Nur Rofiq et al., 2021)

Gambar 15. Tampilan Output Data Nasabah

Output di atas merupakan data nasabah pada Halaman Utama aplikasi Bank Sampah 'Jawara' di Sawah Baru, Ciputat - Tangerang Selatan.

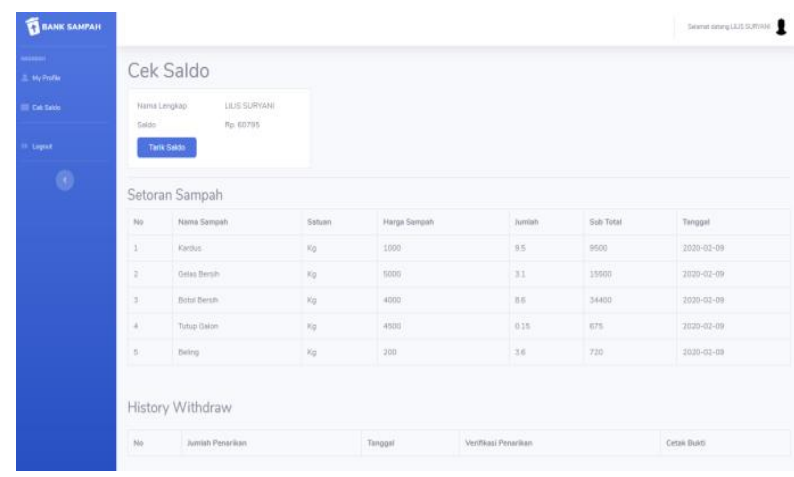

Sumber : (Nur Rofiq et al., 2021) Gambar 16. Tampilan Output Cek Saldo

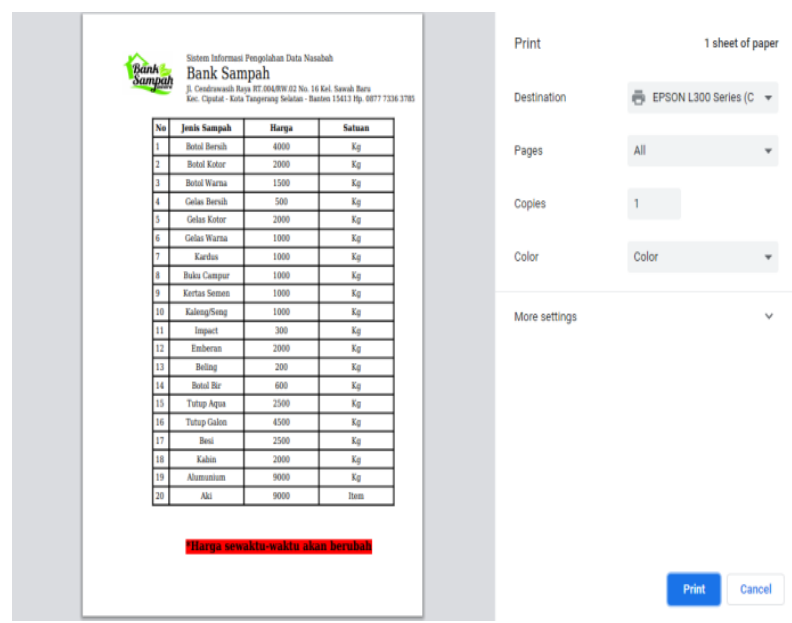

Sumber : (Nur Rofiq et al., 2021)

Gambar 17. Tampilan Output Cetak Daftar Jenis Sampah

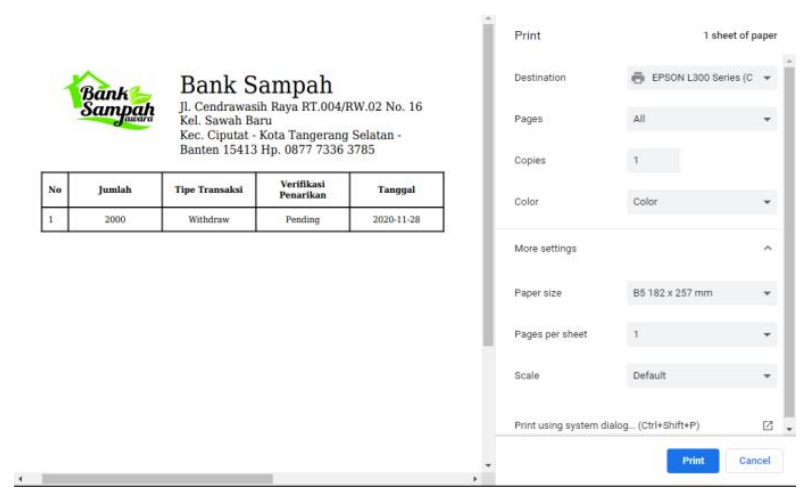

Sumber : (Nur Rofiq et al., 2021)

Gambar18. Tampilan Output Cetak Bukti Transaksi Withdraw

\section{KESIMPULAN}

Berdasarkan hasil penelitian yang dilakukan dalam penerapanaplikasi Bank Sampah 'Jawara'di Sawah Baru, Ciputat-Tangerang dengan metode Waterfall dapat disimpulkan bahwa: Aplikasi ini menjadi solusi dalam penggunaan yang sebelumnya masih menggunakan cara semi komputerisasi dalam mencatatkan setoran sampah nasabah pada file excel. Aplikasi ini menjadi solusi dalam pembuatan laporan daftar harga sampah yang cepat dan rinci. Aplikasi ini mempermudah proses data nasabah serta mempercepat pencarian informasi yang dibutuhkan. Dan aplikasi ini mempermudah untuk nasabah melihat histori transaksi withdraw dan penyetoran yang sebelumnya masih menggunakan cara semi komputerisasi dalam mencatatkan setoran atau withdraw nasabah pada buku tabungan.

\section{DAFTAR PUSTAKA}

Ali, H., \& Limakrisna, N. (2013). Metodologi Penelitian (Petunjuk Praktis untuk Pemecahan Masalah Bisnis, Penyusunan Skripsi, Tesis, dan Disertasi) (1 ed.). Yogyakarta: Deepublish.

Blight, J., Chessell, A. E., Gale, M. J., \& Sharp, C. E. (2008, October 30). United States Patent No. US20080270212A1.

Budiyantara, A., \& Suhartono, J. (2017). Perancangan E-Human Resource Management Berbasis Web Pada Pt. Std. Infotech: Journal of Technology Information, 3(2), 29-35. 
Darono, H. E. (2019, September). Penerapan Metode Waterfall Pada Sistem Pelayanan Berobat Balai Pemeliharaan Kesehatan Medifarma Berbasis Desktop. Jurnal Perspektif, 17(2), 111-118.

Fathony, A. M., Brata, A. H., \& Jonemaro, E. M. (2020, September). Pengembangan Aplikasi Pembayaran Tagihan Listrik berbasis Web (Studi Kasus : Griya Bayar Respon). Jurnal Pengembangan Teknologi Informasi dan Ilmu Komputer, 4(9), 3100-3107.

Husain, T. (2017, Desember). Analisis Dan Perancangan Sistem Informasi Penjualan Produk Kesehatan Pada PT. ABC. ULTIMA InfoSys, $\operatorname{VIII}(2), 101-106$.

Husain, T. (2017, Oktober). Rancang Bangun Sistem Informasi Perekrutan Calon Guru Baru di SMP IT Pesantren Nururrahman. Jurnal Cendikia, 14(1), 1-6.

Husain, T. (2019, December 29). An Analysis of Modeling Audit Quality Measurement Based on Decision Support Systems (DSS). European Journal of Scientific Exploration, 2(6), 1-9.

Jaiman, F., Syaminan, \& Wiguna, A. S. (2019). Sistem Penjemuran Otomatis Menggunakan Arduino Uno R3 dengan Pendekatan Metode Naive Bayes. Seminar Nasional FST 2019. 2, pp. 645655. Malang: Universitas Kanjuruhan Malang.

Kahfi, A. (2017, Juni). Tinjauan terhadap Pengelolaan Sampah. Jurnal Jurisprudentie, 4(1), 12-25.

Loeb, S., Dynarski, S. M., McFarland, D. A., Morris, P., Reardon, S., \& Reber, S. J. (2017). Descriptive Analysis in Education: A Guide for Researchers (NCEE 2017-4023). Washington, DC: The National Center for Education Evaluation and Regional Assistance (NCEE).

Petersen, K., Wohlin, C., \& Baca, D. (2009). The Waterfall Model in Large-Scale. In F. Bomarius, M. Oivo, P. Jaring, \& P. Abrahamsson (Ed.), PROFES 2009 Lecture Notes in Business Information Processing. 32, pp. 386-400. Berlin: Springer-Verlag Berlin Heidelberg.

Putra, I. P., \& Suardika, I. G. (2020). Sistem Informasi Pengelolaan Bank Sampah di Desa Adat Pemogan Berbasis Framework Laravel. Seminar Nasional Teknologi Komputer \& Sains (SAINTEKS) 2020 (pp. 74-81). Medan: STMIK Budi Darma.
Ramdhan, W., Yusda, R. A., Syafwan, H., \& Pratiwi, D. E. (2019). Implementasi Metode Waterfall Pada Perancangan E-Recycle Bank Pada Dinas Lingkungan Hidup Kabupaten Asahan. Prosiding Seminar Nasional Riset Information Science (SENARIS) 2019. Tantangan di Era Revolusi Industri 4.0 Bagi Perguruan Tinggi Di Indonesia, pp. 1010-1017. Pematang Siantar: STIKOM Tunas Bangsa.

Riyanto, A. D., \& Kusumastuti, G. (2015, Agustus). Pembangunan Sistem Informasi Pengolahan Data pada Tabungan Bank Sampah "CERIA" Purwokerto. Jurnal Telematika, 8(2), 1-17.

Rosa, A., \& Shalahuddin, M. (2014). Rekayasa Perangkat Lunak (Vol. Cet.II). Bandung: Informatika.

Samsoni, \& Budiawan, P. (2019). Perancangan Sistem Informasi Pelayanan Klinik Sunan Kalijaga berbasis Dekstop dengan Model Waterfall. Prosiding Seminar Informatika dan Sistem Informasi. 4, pp. 75-88. Tangerang: Teknik Informatika, Universitas Pamulang.

Samudi, Brawijaya, H., \& Widodo, S. (2018, February). Penerapan Metode Waterfall dalam Sistem Informasi Bank Sampah Berbasis Web. JITK (Jurnal Ilmu Pengetahuan dan Teknologi Komputer), 3(2), 245-250.

Sarmidi, Sri Mulyani, E. D., Wiyono, R. A., \& Gunawan. (2019). Sistem Informasi Warga (SIMWARGA) Tingkat RT/RW Berbasis Web. Seminar Nasional Pengabdian (SNP) Masyarakat (pp. 447-454). Makassar: STMIK Dipanegara Makassar.

SIPPa. (2017). Fasilitasi Penyusunan Rencana Induk Sistem Penanganan Persampahan Kabupaten Solok. Subdit Keterpaduan Pemrograman, Direktorat Jenderal Cipta Karya. Jakarta: Team SIPPa.

Tabrani, M. (2017, Desember). Penerapan Metode Waterfall pada Sistem Informasi Inventori PT. Pangan Sehat Sejahtera. Jurnal Inkofar, 1(2), 30-40.

Wiguna, A. S., \& Harianto, W. (2018, Oktober). Sistem Informasi Pemilihan Perumahan Terbaik. SMARTICS Journal, 4(2), 49-51. 